\title{
Intergenic transcription by RNA Polymerase II coordinates Pol IV and Pol V in siRNA-directed transcriptional gene silencing in Arabidopsis
}

\author{
Binglian Zheng, ${ }^{1}$ Zhengming Wang, ${ }^{1,2}$ Shengben $\mathrm{Li}^{1}{ }^{1}$ Bin $\mathrm{Yu}^{1,3}$ Jin-Yuan Liu, ${ }^{2}$ and Xuemei Chen ${ }^{1,4}$ \\ ${ }^{1}$ Department of Botany and Plant Sciences and Institute of Integrative Genome Biology, University of California at Riverside, \\ Riverside, California 92521, USA; ${ }^{2}$ Laboratory of Molecular Biology and Protein Science Laboratory of the Ministry of Education, \\ Department of Biological Sciences and Biotechnology, Tsinghua University, Beijing 100084, Peoples Republic of China
}

\begin{abstract}
Intergenic transcription by RNA Polymerase II (Pol II) is widespread in plant and animal genomes, but the functions of intergenic transcription or the resulting noncoding transcripts are poorly understood. Here, we show that Arabidopsis Pol II is indispensable for endogenous siRNA-mediated transcriptional gene silencing (TGS) at intergenic low-copy-number loci, despite the presence of two other polymerases-Pol IV and Pol V-that specialize in TGS through siRNAs. We show that Pol II produces noncoding scaffold transcripts that originate outside of heterochromatic, siRNA-generating loci. Through these transcripts and physical interactions with the siRNA effector protein ARGONAUTE4 (AGO4), Pol II recruits AGO4/siRNAs to homologous loci to result in TGS. Meanwhile, Pol II transcription also recruits Pol IV and Pol V to different locations at heterochromatic loci to promote siRNA biogenesis and siRNA-mediated TGS, respectively. This study establishes that intergenic transcription by Pol II is required for siRNA-mediated TGS, and reveals an intricate collaboration and division of labor among the three polymerases in gene silencing.
\end{abstract}

[Keywords: RNA polymerase; siRNA; DNA methylation; transcriptional gene silencing; noncoding transcripts]

Supplemental material is available at http://www.genesdev.org.

Received September 26, 2009; revised version accepted October 26, 2009.

One prominent role of transcriptional gene silencing (TGS) is defense against the proliferation of transposable elements and repeats (Moazed 2009). In Arabidopsis, silencing at endogenous repeat loci involves histone modifications, such as dimethylation at histone $\mathrm{H} 3$ Lys 9 (H3K9me2), and RNA-directed DNA methylation (RdDM) guided by homologous siRNAs (Hamilton et al. 2002; Zilberman et al. 2003; Xie et al. 2004). Players in RdDM in Arabidopsis include RNA-DEPENDENT RNA POLYMERASE2 (RDR2), ARGONAUTE4 (AGO4), AGO6, and DICER-LIKE3 (DCL3) (Zilberman et al. 2003; Xie et al. 2004; Zheng et al. 2007). RDR2 is thought to copy ssRNA from a heterochromatic locus into dsRNA. DCL3 cleaves the dsRNA into 24-nucleotide (nt) siRNA duplexes, one strand of which associates with AGO4 (or AGO6) to form an RNA-induced silencing complex (RISC). AGO4 RISC recruits, directly or indirectly, the de novo DNA methyltransferase DRM2 to genomic loci

\footnotetext{
${ }^{3}$ Present address: Center for Plant Science innovation, University of Nebraska, Lincoln Lincoln, NE 68588, USA.

${ }^{4}$ Corresponding author.

E-MAIL xuemei.chen@ucr.edu; FAX (951) 827-4437.

Article published online ahead of print. Article and publication date are online at http://www.genesdev.org/cgi/doi/10.1101/gad.1868009.
}

homologous to the siRNAs to trigger DNA methylation (Cao et al. 2003). An AGO4 RISC complex may also guide H3K9 methylation by recruiting the SUVH family of histone methyltransferases (Malagnac et al. 2002; Ebbs et al. 2005; Naumann et al. 2005; Ebbs and Bender 2006).

In fission yeast, siRNA-mediated formation of heterochromatin at pericentromeric repeats depends on RNA Polymerase II (Pol II) transcription of the repeats (Volpe et al. 2002; Djupedal et al. 2005; Kato et al. 2005). The Pol II-generated noncoding RNAs have a dual function in heterochromatin assembly, serving as both precursors to siRNAs and scaffolds that interact with siRNAs to recruit chromatin-modifying factors (Djupedal et al. 2005; Kato et al. 2005). Nonlethal mutations that disrupt siRNA-mediated gene silencing and/or siRNA accumulation in Schizosaccharomyces pombe have been mapped to RPB2 and RPB7, two subunits of Pol II (Djupedal et al. 2005; Kato et al. 2005).

Plants have evolved from Pol II two additional RNA polymerases-Pol IV and Pol V-to specialize in siRNA production and siRNA-mediated gene silencing, respectively (Herr et al. 2005; Kanno et al. 2005; Onodera et al. 2005; Pontier et al. 2005). Many subunits of Pol IV or Pol V have identical or paralogous counterparts in Pol II, 
indicating that they are derived from Pol II (Huang et al. 2009; Lahmy et al. 2009; Ream et al. 2009). The largest subunits of Pol II, Pol IV, and Pol V are distinct from one another (encoded by NRPB1, NRPD1, and NRPE1, respectively). Pol IV and Pol V share the same second largest subunit (encoded by NRPD2/NRPE2), which is distinct from that of Pol II (encoded by NRPB2). While null mutations in Pol II genes are lethal (Onodera et al. 2008), those in Pol IV- or Pol V-specific genes do not lead to strong visible defects, but result in transcriptional derepression of transposons and repeat loci throughout the genome. Pol IV acts at an early step in the RdDM pathway to generate 24-nt siRNAs, probably by transcribing heterochromatic loci to produce precursor RNAs (Herr et al. 2005; Kanno et al. 2005; Onodera et al. 2005). Pol V is required for siRNA-mediated silencing of target sequences, probably by recruiting AGO4 RISCs through RNA transcripts that it generates at the target loci and by physically interacting with AGO4 through its GW/WG motifs (Li et al. 2006; El-Shami et al. 2007; Wierzbicki et al. 2008, 2009). In nrpe1 mutants, siRNA accumulation is reduced in a subset of the Pol IVdependent loci but is unaffected in other loci (Pontier et al. 2005; Huettel et al. 2006). It is thought that the role of Pol V in siRNA accumulation at some loci is an indirect consequence of its function in heterochromatin formation, which in turn promotes siRNA production.

The presence of two polymerases specializing in TGS in plants raises the question of whether or not the plant Pol II has any role in TGS. The isolation of a weak allele in the gene encoding the second largest subunit of Pol II, NRPB2, allowed us to assess Pol II's role in TGS. Despite the weak nature of the mutation, it results in the derepression of a set of intergenic low-copy-number repeat sequences. Pol II acts in siRNA-mediated DNA and histone methylation by recruiting AGO4 and Pol V to the silenced loci through both physical interactions with AGO4 and scaffold transcripts that it generates adjacent to the silenced loci. In addition, Pol II, but not Pol V, acts in the feed-forward loop to promote siRNA accumulation from these loci by recruiting Pol IV to chromatin. Our studies show that Pol II, Pol IV, and Pol V have nonredundant roles, thus revealing a more complex TGS mechanism with noncoding transcription by Pol II playing a central role in coordinating the other two polymerases.

\section{Results}

\section{Isolation of a weak mutant allele of NRPB2}

In an ethyl methanesulfonate mutagenesis screen aimed at the isolation of mutants compromised in microRNA (miRNA) biogenesis, we isolated a mutant with pleiotropic developmental phenotypes that are also exhibited by known mutants in miRNA biogenesis genes. The defects included distorted leaf shape, delayed leaf emergence, reduced number of floral organs, abnormal phyllotaxy, and shorter siliques (Fig. 1A; data not shown). Genetic studies showed that these morphological defects were controlled by a single, recessive mutation. The mutation
$\mathbf{A}$
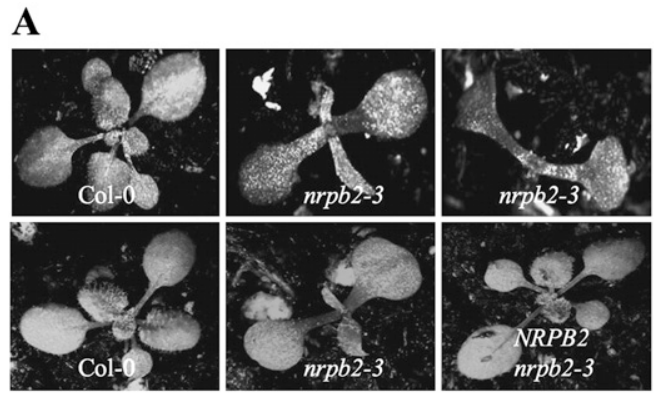

C

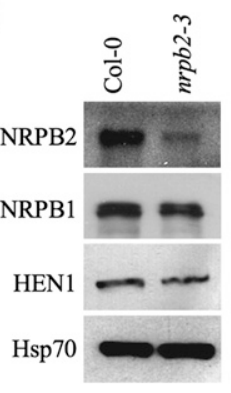

B

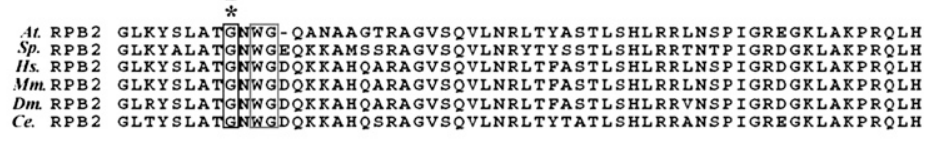

At. RPB 2 NSQWGMMCPAETPEGQACGLVRNLALMVY ITVGSAAYP ILEFLEEWGTENFEEI SPSVIP Sp. RPB 2 NTHWGLVCPAETPEGQACGLVKNLSLMSCISVGTDPMPIITFLSEWGMEPLEDY YPHQSP
II. RPB2 11. RPB2 2 NTLWGMVCPAETPEGHAVGLVKNLALMAYI SVGSQPSPILEFLEEWSMENLEEI SPAAIA
Mm.RPB2 NTLWGMVCPAETPEGHAVGLVKNLALMAYISVGSQPSPILEFLEEWSMENLEEI SPAAIA Dm. RPB 2 NTLWGML CPAETPEGAAVGLVKNLALMAYISVGSOPSPILEFLEEWSMENLEEIAPSAIA

Ce. RPB 2 NTQWGMVCPAETPEGQAVGLVKNLALMAYISVGSLPEPILEFLEEWSMENLEEV SPSAIA

At. RPB 2 QATRI FVNGMWVGVHRDPDMLVKTLRRLRRRVDVNT - EVGVVRDIRLKELRIYTDYGRCS Sp. RPB 2 DATRVPVNGVWHGVHRNPARLMETLRTLRRKGDINP - EVSMIRDIREKELKIFTDAGRVY IIs. RPB2 DATKIFVNGCWVGIHKDPEQLMNTLRKLRRQMDIIVSEVSMIRDIREREIRIYTDAGRIC

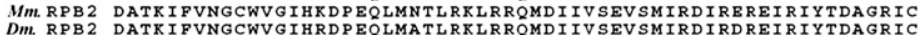
Ce. RPB 2 DATKIFVNGAWVIHREPDQLMTLKKLRRQMDIIVSEVSMVRIRDREIRIYTDAGRVC

4t. RPB 2 RPLFIVDN-- - - - QRLLIKKRDIYALQQR - - - - - - ESAEED GWHHLVAKG SP. RPB2 RPLFIVEDDESLGHKELRVRKGHIAKLMATEYQDIEGGFEDVEEYTWSSLLNEG Mm.RPB2 RPLLIVER-1.- R Dm. RPB2 RPLLIVEN- - . - - GSLLLKRTHVEMLKER - . . . . . - DYNNY - SWLVLVASG

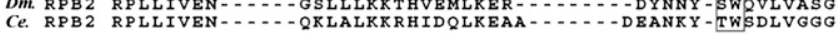

Figure 1. Isolation of an nrpb2 mutant. (A) Three-weekold seedlings of various genotypes as indicated. (NRPB2 nrpb2-3) An nrpb2-3 mutant carrying an NRPB2 transgene. Note that the photos of the mutant plants were taken at a higher magnification than those of the wildtype and the rescued line. (B) Partial amino acid sequence of RPB2 in various species. The conserved glycine, which was mutated to glutamic acid in nrpb2-3, is marked by a rectangle and an asterisk. The other rectangles show GW/WG motifs in RPB2 proteins. (At) Arabidopsis thaliana; (Sp) Schizosaccharomyces pombe; (Hs) Homo sapiens; $(\mathrm{Mm})$ Mus musculus; $(\mathrm{Dm})$ Drosophila melanogaster; $(\mathrm{Ce})$ Caenorhabditis elegans. (C) Western blotting to determine the levels of NRPB2 and NRPB1 in wild type (Col-0) and nrpb2-3. HEN1 and Hsp70 served as loading controls. 
responsible for the morphological defects was mapped to a $206-\mathrm{kb}$ region on chromosome IV. Sequencing candidate genes in this region identified a G-to-A mutation in the coding region of NRPB2, which encodes the secondlargest subunit of Pol II. This mutation caused a conversion of a highly conserved glycine in RPB2 proteins from $S$. pombe, animals, and plants to glutamic acid (Fig. 1B). An NRPB2 genomic fragment, when introduced into this mutant, completely rescued the phenotypes in 51 out of $58 \mathrm{~T} 1$ transgenic lines. (Fig. 1A; data not shown). Therefore, the mutant is an allele of NRPB2. Two previously isolated loss-of-function alleles of NRPB2-nrpb2-1 and nrpb2-2-are embryo-lethal, consistent with the essential role of Pol II in nuclear gene expression (Onodera et al. 2005, 2008). We named this new mutant nrpb2-3. Consistent with its being a weak allele, NRPB2 protein still accumulated, but at a reduced level in the mutant (Fig. 1C). Levels of NRPB1, the largest subunit of Pol II, remained largely unchanged (Fig. 1C). To minimize differences in tissue composition between wild-type and nrpb2-3 samples, we used inflorescences, which appeared to be the least affected in nrpb2-3, for all studies described below.

\section{The expression of a small set of genes is affected} in nrpb2-3

We next examined the effects of the nrpb2-3 mutation on gene expression at the transcriptome level using ATH1 Affymetrix microarrays. RNAs from inflorescence tissues from three biological replicates of wild type and nrpb2-3 were compared. A total of 448 genes were reduced in expression by twofold in nrpb2-3 (Supplemental Table S1), and 95 genes were increased in expression by twofold in nrpb2-3 (Supplemental Table S2). Most affected genes encode metabolic enzymes, and no genes known to play a role in siRNA biogenesis or siRNA-mediated TGS were affected. Real-time RT-PCR confirmed that genes with known roles in siRNA biogenesis, DNA methylation or demethylation, and histone H3K9me2 were not affected by the nrpb2-3 mutation (Supplemental Fig. S1). Therefore, the effects of $n r p b 2-3$ on small RNA biogenesis or TGS (see below) are unlikely to be attributable to indirect effects of the mutation on the expression of these genes. We suspect that some of the developmental defects of the mutant were caused by reduced miRNA levels (data not shown).

\section{Role of Pol II in the accumulation of heterochromatic SiRNAs}

We classified heterochromatic loci into two types according to their dependence on Pol IV and Pol V for siRNA accumulation (Zhang et al. 2007; Mosher et al. 2008). Type I loci are high-copy-number repeats or transposons, such as AtSN1, siR1003, AtREP2, SimpleHAT2, and AtCopia2. siRNA levels from these loci are Pol IV- and Pol V-dependent (Herr et al. 2005; Onodera et al. 2005; Pontier et al. 2005). Type II loci are represented by lowcopy-number repeats and intergenic sequences, such as siR02, Cluster4, TR2558, Cluster2, and soloLTR. siRNAs from these loci are Pol IV-dependent but Pol V-independent (Pontier et al. 2005; Huettel et al. 2006).
Five type I siRNAs accumulated to comparable levels in nrpb2-3 and wild type, but were absent in sde4-3 (a Pol IV mutant) and greatly reduced in abundance in nrpe1-1 (a Pol V mutant) (Fig. 2A). For type II siRNAs, the levels of all tested siRNAs were slightly reduced in nrpb2-3 compared with wild type (Fig. 2B,C). Although the differences were small, the reduction was highly reproducible in three to five biological replicates for each siRNA loci tested. siR02 was the most severely affected locus, with a $67 \%$ reduction in siRNA levels in nrpb2-3 (Fig. 2B). Note that the reduction in type II siRNA levels in the nrpb2-3 mutant was rescued by NRPB2 genomic DNA (Fig. 2B,C), indicating that the siRNA defects were caused by the nrpb2-3 mutation. In addition, we did not observe any reduction in type II siRNA levels in nrpe1-1 (Fig. $2 \mathrm{~B}, \mathrm{C})$, consistent with findings from previous studies (Pontier et al. 2005; Huettel et al. 2006; Mosher et al.

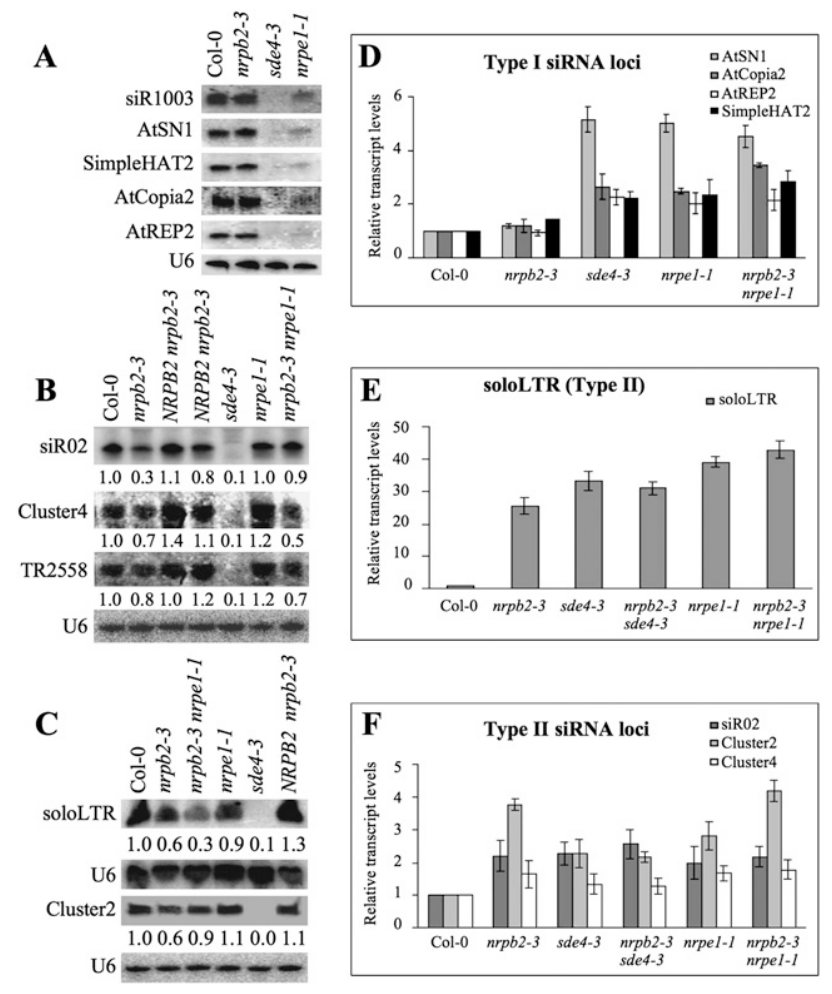

Figure 2. siRNA accumulation and TGS at heterochromatic loci in various genotypes. $(A-C)$ siRNA accumulation in various genotypes. (Col-0) Wild type; (nrpb2-3) a Pol II mutant; (sde4-3) a Pol IV mutant; (nrpe1-1) a Pol V mutant; (NRPB2 nrpb2-3) the nrpb2-3 mutant complemented with NRPB2 genomic DNA; two independent transgenic lines were included in $B$. The numbers below the gel images indicate the relative levels of an siRNA among the different genotypes. The U6 blots served as loading controls for the small RNA blots above. $(D-F)$ Real-time RT-PCR analysis of the expression of siRNA loci in various genotypes. Transcripts from the siRNA-generating region (region A in Fig. 3A) were detected. Transcript levels were normalized to those of $U B Q 5$ and the mutants were compared with wild type. Standard deviations were calculated from three technical replicates. The results shown were reproduced with three biological replicates. 
2008). These results indicate that Pol II, but not Pol V, promotes the biogenesis of type II siRNAs.

\section{Role of Pol II in TGS of type II siRNA loci}

We next examined whether Pol II plays a role in siRNAmediated TGS. We divided the siRNA loci into regions A and $\mathrm{B}$, which represent the immediate siRNA-generating regions and the adjacent regions, respectively (Fig. 3A). We determined transcript levels from the siRNA-generating region A by real-time RT-PCR as a measure of the silencing status of the loci, as done in previous studies (Xie et al. 2004; Herr et al. 2005; Kanno et al. 2005; Huettel et al. 2006). Transcripts from type I loci accumulated at two to six times the wild-type levels in sde4-3 and nrpe1-1, indicating derepression of these loci in Pol IV and Pol V mutants (Fig. 2D; Xie et al. 2004; Herr et al. 2005; Kanno et al. 2005). In contrast, transcript levels from type I loci in nrpb2-3 were similar to those in wild type. However, since nrpb2-3 is a weak allele, the potential role of Pol II in TGS at type I loci cannot be excluded. In fact, we observed a small increase in expression at SimpleHAT2 and AtCopia2 in the nrpb2-3 nrpe1-1 double mutant as compared with the nrpe1-1 single mutant (Fig. 2D).

For type II siRNA loci such as soloLTR, siR02, Cluster4, and Cluster2, we found similar amplitudes of derepression in nrpb2-3 as compared with sde4-3 or nrpe1-1 (Fig. 2E,F). We next asked whether the silencing effect of NRPB2 at type II loci was mediated by siRNAs or by an
A
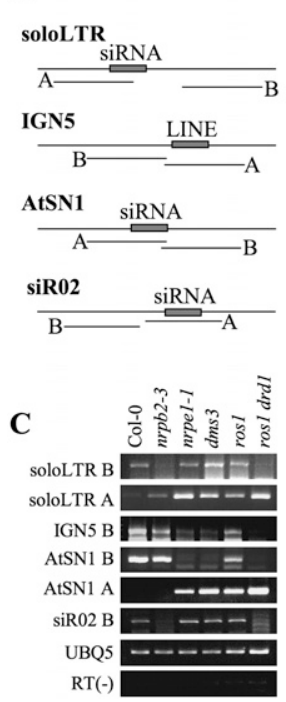

B

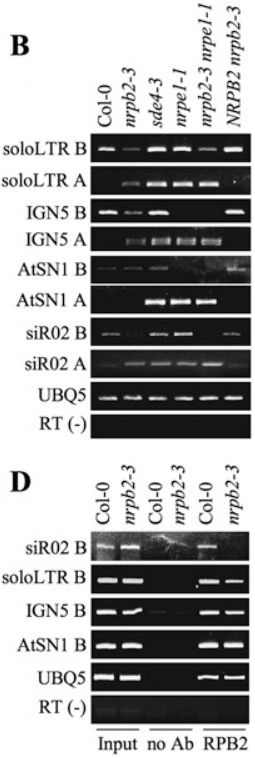

Figure 3. Detection of noncoding transcripts at siRNA loci. $(A)$ Diagrams of soloLTR, IGN5, AtSN1, and siR02 genomic regions. The soloLTR, IGN5, and AtSN1 regions are based on analysis of transcription units by Wierzbicki et al. (2008). (B,C) RT-PCR analysis of noncoding transcripts at siRNA loci in various genotypes. $(D)$ RIP with anti-RPB2 antibodies to test the association of Pol II with noncoding transcripts at siRNA loci. In $B-D$, $U B Q 5$ served as a loading control. The RT $(-)$ control PCR was performed with $U B Q 5$ primers. The results shown were reproduced at least three times.
siRNA-independent mechanism. We examined the amplitudes of derepression in the nrpb2-3 sde4-3 double mutant in comparison with the sde4-3 single mutant, which completely lacks siRNAs from these loci. If the derepression effects observed in nrpb2-3 are siRNAdependent, there should not be any additive effects in the double mutant. There was no difference in transcript levels at the type II loci between sde4-3 and nrpb2-3 sde4-3 (Fig. 2E,F), suggesting that NRPB2 acts through an siRNA-dependent mechanism. The similar amplitudes of derepression between Pol II and Pol IV mutants also suggested that the lack of TGS in the Pol II mutant was unlikely attributable to the small reduction in siRNA accumulation. Rather, Pol II likely acted downstream from siRNAs in TGS. Despite normal siRNA accumulation, type II siRNA loci were derepressed in nrpe1-1 (Fig. $2 \mathrm{E}, \mathrm{F}$ ), consistent with previous reports (Huettel et al. 2006). Therefore, Pol V also acted downstream from the siRNAs in the silencing of type II loci. The amplitudes of type II loci derepression were comparable between the nrpb2-3 nrpe1-1 double mutant and either single mutant (Fig. 2E,F), suggesting that Pol II and Pol V had nonredundant functions in the silencing of type II loci. Indeed, we observed a severe reduction in DNA methylation at siR02 (Supplemental Fig. S2A) and a reduction in H3K9me2 at most type II loci examined (Supplemental Fig. S2B) in both nrpb2-3 and nrpe1-1.

\section{Pol II generates transcripts from adjacent regions of type II siRNA loci}

Pol V generates specific RNA transcripts originating outside of some siRNA-producing loci, and these transcripts likely serve as scaffolds to recruit AGO4/siRNA RISCs to homologous genomic loci to facilitate RdDM (Wierzbicki et al. 2008, 2009). Intriguingly, RNA transcripts originating outside of the soloLTR locus (i.e., the scaffold transcripts) were present in wild-type plants and were just as abundant in the nrpe1-1 mutant, and chromatin immunoprecipitation (ChIP) detected the presence of not only Pol V but also Pol II at the soloLTR chromatin (Wierzbicki et al. 2008). Given our finding that soloLTR was greatly derepressed in nrpb2-3, we hypothesized that Pol II was responsible for transcribing soloLTR-specific scaffold transcripts. To test this hypothesis, we detected transcripts from different positions near the soloLTR locus by RT-PCR (Fig. 3A,B). For the soloLTR B fragment (representing the scaffold transcript-generating region), we observed greatly reduced transcript levels in nrpb2-3 (Fig. 3B). Consistent with previous findings (Wierzbicki et al. 2008), the transcript levels were not affected in either the nrpe1-1 or the sde4-3 mutant (Fig. 3B). Transcript levels from region A were increased in nrpb2-3, sde4-3, and nrpe1-1 mutants relative to wild type (Fig. 3B), consistent with the derepression of this locus in mutants of all three polymerases.

We tested the accumulation of other Pol V-dependent scaffold transcripts detected by Wierzbicki et al. (2008) in nrpb2-3. At AtSN1 (a type I locus), transcripts from region A were greatly elevated in sde4-3, nrpe1-1, and nrpb2-3 
nrpe1-1, but not in nrpb2-3 (Fig. 3A,B), consistent with derepression of AtSN1 in the first three genotypes but not in nrpb2-3 (Fig. 2D). The scaffold transcripts from region B were diminished in nrpe1-1 but not affected in nrpb2-3 (Fig. 3B). Surprisingly, at IGN5, an intergenic noncoding region for which scaffold transcripts were Pol V-dependent (Wierzbicki et al. 2008), we also detected reduced transcript levels in the nrpb2-3 mutant (IGN5 B) (Fig. $3 \mathrm{~A}, \mathrm{~B})$. Consistently, derepression of IGN5 was observed in nrpb2-3 as well as nrpe1-1 (IGN5 A) (Fig. 3A,B).

Next, we tested whether Pol II generated transcripts from siR02, another type II locus like soloLTR and IGN5. For the immediate siRNA-producing region (region A), transcripts were found at elevated levels in nrpb2-3, sde4-3, and nrpe1-1 mutants (Fig. 3B), consistent with derepression of siR02 in the three genotypes (Fig. 2F). Potential scaffold transcripts from region B (Fig. 3A) were also detected, and they were greatly reduced in nrpb2-3 but unaffected in either Pol IV or Pol V mutants (Fig. 3B). Note that at all type II loci tested, the lack of, or reduced levels of, transcripts from region $\mathrm{B}$ was always accompanied by derepression at region $\mathrm{A}$ in the nrpb2-3 mutant, implying that the Pol II transcripts were important for silencing. The fact that both defects were rescued simultaneously by the NRPB2 genomic DNA (Fig. 3B) confirmed that the molecular defects were due to the nrpb2-3 mutation.

The accumulation of Pol V-dependent scaffold transcripts requires DRD1, an SNF2-like chromatin remodeling protein, and DMS3, a structural maintenance of chromosome hinge domain-containing protein, both of which are required for RdDM (Kanno et al. 2004, 2008). We tested whether the two genes are required for the accumulation of Pol II-dependent transcripts at type II loci by RT-PCR. Consistent with previous observations, Pol V-dependent transcripts from IGN5 B and AtSN1 B were diminished in the $d m s 3$ mutant (Fig. 3C; Wierzbicki et al. 2009). However, the Pol II-dependent transcripts at soloLTR and siR02 were not affected (Fig. 3C). The effects of $d r d 1$ were assayed in the ros 1 background; compared with the ros 1 single mutant, the ros 1 drd1 double mutant lacked both Pol II-dependent transcripts at type II loci as well as Pol V-dependent transcripts at type I loci (Fig. 3C). DRD1 was found previously to be required for the accumulation of Pol V-dependent scaffold transcripts (Wierzbicki et al. 2008). Taken together, this study and previous studies show that DMS3 is specifically required for the accumulation of Pol V transcripts, and DRD1 is required for the accumulation of both Pol II- and Pol V-dependent scaffold transcripts.

Next, we tested whether Pol II was associated with the Pol II-dependent transcripts at type II loci by RNA immunoprecipitation (RIP). Anti-RPB2 polyclonal antibodies were used to immunoprecipitate NRPB2, and the associated RNAs were detected by RT-PCR. Two biological replicates gave identical results. While no transcripts were detected in the "no antibody" immunoprecipitate, Pol II-dependent transcripts at siR02 and soloLTR were coprecipitated with Pol II (Fig. 3D). In the nrpb2-3 mutant, the abundance of the Pol II-associated RNAs was reduced, as expected (Fig. 3D). Pol II was also associated with Pol V-dependent scaffold transcripts at AtSN1 (Fig. 3D).

\section{Association of Pol II with the chromatin at siRNA loci}

To determine whether Pol II has a direct role in the production of the Pol II-dependent transcripts and in TGS at type II loci, we first examined Pol II occupancy at type II chromatin by ChIP using an anti-RPB1 antibody. eIF4A1 served as a positive control, whereas the same ChIP procedure performed without an antibody served as a negative control. Real-time PCR of coprecipitated DNA showed that all tested loci were enriched in the Pol II immunoprecipitate relative to the "no antibody" immunoprecipitate, suggesting that Pol II was present at all silenced loci in both regions A and B (Fig. 4). The presence of Pol II at soloLTR was also detected in a previous study (Wierzbicki et al. 2008). Interestingly, Pol II was also detected at regions $\mathrm{A}$ and $\mathrm{B}$ of AtSN1, a type I locus in two biological replicates (Fig. 4A, B; data not shown), whereas a previous study did not observe Pol II occupancy at AtSN1 above the levels for their "no antibody" control (Wierzbicki et al. 2009). The differences in the two studies could be due to different antibodies used against Pol II. At all tested loci, Pol II occupancy at region A was independent of Pol IV or Pol V (Fig. 4A) and, in the case of soloLTR, was slightly increased in the Pol II, Pol IV, and Pol V mutants, suggesting that Pol II transcribes the soloLTR region A when it is derepressed. Pol II occupancy at region $\mathrm{B}$ at all tested loci was also independent of Pol IV or Pol V (Fig. 4B).

\section{Recruitment of AGO4 to type II siRNA loci by Pol II}

Since 24-nt siRNAs are bound by the effector protein AGO4 to result in TGS, and Pol II is required for TGS at type II loci, we asked whether Pol II recruits AGO4/siRNAs
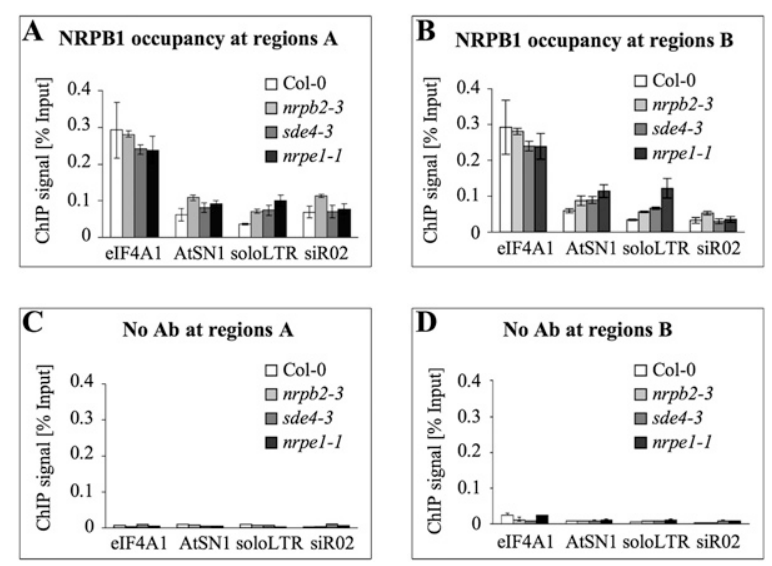

Figure 4. Pol II is present at siRNA loci. $(A, B)$ Real-time PCR of DNA that copurified with Pol II in ChIP performed in various genotypes with an anti-RPB1 antibody. The eIF4A1 gene served as a positive control. $(C, D)$ The "No Ab" (no antibody) immunoprecipitate served as negative controls. The ChIP signal was quantified as the percentage of total input DNA. Two biological replicates were performed and identical results were obtained. Standard deviations were calculated from three technical repeats. 
to type II loci. We crossed a functional myc-AGO4 transgene (Li et al. 2006) into the nrpb2-3 background and performed ChIP using an anti-myc antibody to examine the occupancy of myc-AGO4 at type I and type II loci. Region A at type I(AtSN1) and type II (soloLTR and siR02) loci, but not the gene eIF4A1, was enriched in the mycAGO4 ChIP (Fig. 5A). AGO4 association to region A of AtSN1 and soloLTR was also detected, and was found to be Pol V-dependent in a previous study (Wierzbicki et al. 2009). Interestingly, myc-AGO4 was not associated with region B of AtSN1, soloLTR, or siR02 (Fig. 5B). mycAGO4 occupancy at region A of soloLTR and siR02 was strongly reduced in the nrpb2-3 mutant, but that at region A of AtSN1 was not (Fig. 5A). Therefore, the dependence on Pol II for AGO4 recruitment at siRNA loci correlates with the production of scaffold transcripts by Pol II. Western blotting showed that myc-AGO4 protein levels were not detectably different between wild type and nrpb2-3 (Supplemental Fig. S3A).

While the Pol II-dependent scaffold transcripts may serve to recruit siRNA/AGO4 RISCs to type II chromatin, physical interaction between Pol II and AGO4 may also contribute to the recruitment of AGO4 to chromatin. The extended C-terminal domain (CTD) of NRPE1 harbors $16 \mathrm{GW} / \mathrm{WG}$ motifs that provide an AGO4-binding platform essential for RdDM (Li et al. 2006; El-Shami et al. 2007). We found four GW/WG motifs in NRPB2, three of which are conserved with those in fission yeast
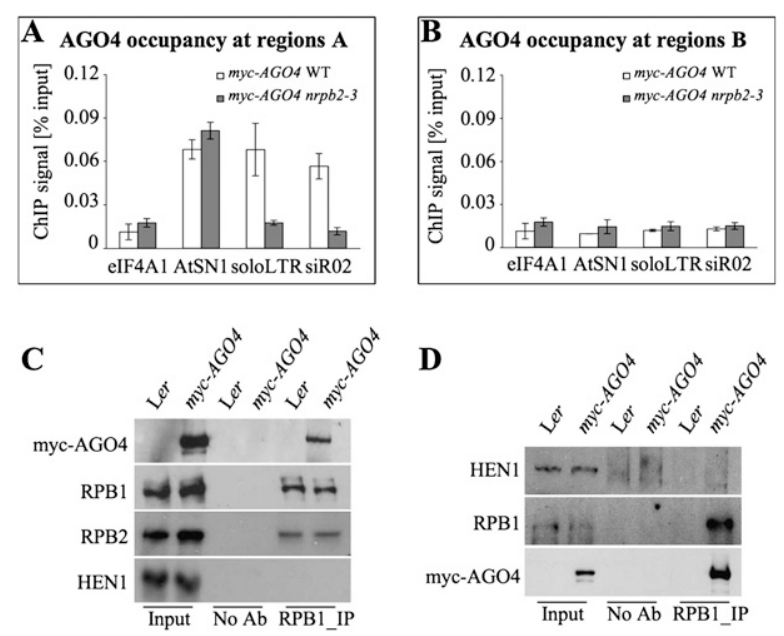

Figure 5. Recruitment of AGO4 by Pol II. $(A, B)$ AGO4 occupancy at regions $\mathrm{A}$ and $\mathrm{B}$ of siRNA loci. ChIP was performed using an anti-myc antibody and DNA that copurified with mycAGO4 was quantified by real-time PCR. Region A, but not B, was enriched in the myc-AGO4 immunoprecipitate, as compared with the eIF4A1 negative control. (WT) Wild type. $(C, D)$ Co-IP to test the association between AGO4 and Pol II in vivo with anti-RPB1 and anti-myc antibodies, respectively. (Ler) Wild type; a negative control for myc-AGO4. Proteins from one-sixth of "No $\mathrm{Ab}^{\prime}$ " (no antibody) immunoprecipitate and one-sixth of immunoprecipitate were analyzed by Western blotting. Proteins from $1 / 100$ of input were included for anti-RPB1, anti-RPB2, and anti-HEN1 blots, while proteins from 1/1000 of input were used for the anti-myc blot.
RPB2 (Fig. 1B). Since one GW/WG motif is sufficient for AGO4 binding in vitro (El-Shami et al. 2007), it is possible that the GW/WG motifs in NRPB2 mediate the interaction between Pol II and AGO4. We first performed coimmunoprecipitation (co-IP) to determine whether Pol II and AGO4 were associated in vivo. Anti-RPB1 antibodies were able to immunoprecipitate NRPB2 as well as NRPB1, as expected (Fig. 5C). Anti-RPB1 antibodies also coprecipitated myc-AGO4, but not HEN1, a negative control (Fig. 5C). Conversely, an anti-myc antibody specifically immunoprecipitated myc-AGO4 and NRPB1, but not HEN1 (a negative control) (Fig. 5D).

We next performed GST pull-down experiments with recombinant NRPB2 expressed in Escherichia coli. A 900-amino-acid region containing the GW/WG motifs (GWR) was fused to GST and purified with glutathione beads. GST-NRPE1 CTD (Li et al. 2006; El-Shami et al. 2007) and GST were also included as a positive and a negative control, respectively. In multiple biological replicates, we observed myc-AGO4, but not HEN1, binding to the NRPB2 GWR and to NRPE1 CTD (Supplemental Fig. S4). The GWR containing the nrpb2-3 mutation (NRPB2-3 GWR) also pulled down myc-AGO4 as efficiently as wild-type GWR (Supplemental Fig. S4). Recombinant GWR with four GW/WG motifs mutated (NRPB2 GWRm) showed reduced binding to AGO4 (Supplemental Fig. S4). These data, together with the co-IP results, strongly suggest that Pol II and AGO4 interact with each other.

\section{Pol II recruits Pol $V$ to type II loci}

At soloLTR, Pol V binds to scaffold transcripts (Wierzbicki et al. 2008), which we showed to be produced by Pol II. Therefore, it is likely that Pol V is recruited to soloLTR chromatin by Pol II-dependent transcripts or the act of Pol II transcription itself. To determine whether the association of Pol V with soloLTR and other type II loci depends on Pol II, we determined Pol V occupancy at regions $\mathrm{A}$ and $\mathrm{B}$ at AtSN1 and two type II loci in wild type and nrpb2-3. A functional NRPE1-Flag transgene (Pontes et al. 2006) was crossed into nrpb2-3 and ChIP was conducted with anti-Flag antibodies. Pol V occupancy at AtSN1 was not affected by the nrpb2-3 mutation in either region $\mathrm{A}$ or B (Fig. 6A,B). However, Pol V occupancy at soloLTR and siR02 was strongly reduced at region $\mathrm{B}$ (Fig. 6B) but largely unaffected at region A (Fig. 6A). This suggests that the Pol II-dependent transcripts or Pol II transcription recruits Pol V to region B of type II loci. Western blots showed that the levels of NRPE1-Flag protein were not different between wild type and nrpb2-3 (Supplemental Fig. S3B).

\section{Pol II recruits Pol IV to type II loci}

We asked how Pol II promotes siRNA biogenesis at type II loci through Pol IV. The molecular function of Pol IV in siRNA biogenesis is still unknown. In one model, Pol IV transcribes heterochromatic chromatin into singlestranded transcripts that serve as siRNA precursors. In another model, Pol IV transcribes double-stranded transcripts generated by RDR2. In nuclei, numerous Pol IV 

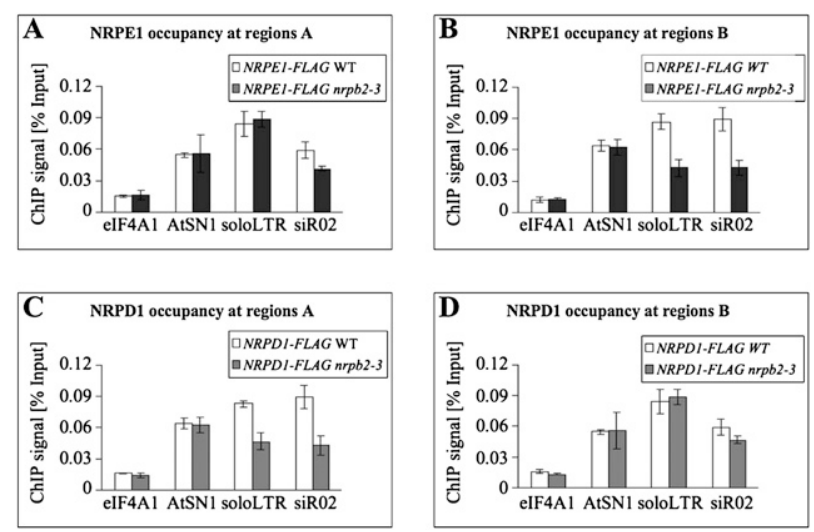

Figure 6. Pol V and Pol IV occupancy at regions A and B of siRNA loci. ChIP was performed against NRPE1-Flag $(A, B)$ or NRPD1-Flag $(C, D)$, and the coprecipitated DNA was quantified by real-time PCR and expressed as the percentage of input DNA. eIF4A1 served as a negative control. Standard deviations were calculated from three technical repeats. The results shown were reproduced in two biological replicates. (WT) Wild type.

foci are sensitive to RNase treatment, suggesting that Pol IV is anchored by RNA (Pontes et al. 2006).

We examined whether Pol IV is present at heterochromatic chromatin, which has not been tested before, and whether its occupancy depends on Pol II. ChIP using antiFlag antibodies against a wild-type line with a functional NRPD1-Flag transgene (Pontes et al. 2006) showed that both regions $\mathrm{A}$ and $\mathrm{B}$ at type $\mathrm{I}$ and $\mathrm{II}$ loci, but not the negative control eIF4A, were enriched in the Pol IV ChIP (Fig. 6C,D). Therefore, Pol IV is present at type I and type II loci, consistent with the known role of Pol IV in siRNA biogenesis at heterochromatic loci but not at genes. We next evaluated whether Pol IV occupancy at these loci depended on Pol II by ChIP from NRPD1-Flag nrpb2-3. Pol IV occupancy at either region A (Fig. 6C) or B (Fig. 6D) of AtSN1 was not affected in the nrpb2-3 mutant, consistent with the lack of an observable effect of the nrpb2-3 mutation on siRNA biogenesis at this locus. At the two type II loci, Pol IV occupancy at region A was strongly reduced in nrpb2-3 (Fig. 6C), whereas that at region $\mathrm{B}$ (Fig. 6D) was not. The levels of NRPD1-Flag were largely the same between wild type and nrpb2-3 (Supplemental Fig. S3C). Therefore, Pol II recruits Pol IV to region A of type II loci for siRNA production.

\section{Discussion}

\section{Pol II has a direct role in TGS}

The isolation of the reduction-of-function nrpb2-3 allele allowed us to address the role of Pol II in heterochromatic siRNA-mediated TGS in Arabidopsis. Pol IV and Pol V share the same second-largest subunit, NRPD2/NRPE2, which is distinct from NRPB2 (Kanno et al. 2005; Onodera et al. 2005; Pontier et al. 2005). Immunoprecipitation using anti-Flag antibodies from an NRPB2-Flag line recovered all 12 Pol II subunits and no subunits specific to
Pol I, Pol III, Pol IV, or Pol V (Ream et al. 2009), suggesting that NRPB2 does not reside in polymerases other than Pol II. Targeted co-IP experiments between NRPB2 and Pol V-specific subunits also demonstrated that NRPB2 is not found in Pol V (Ream et al. 2009). In addition, our findings that some scaffold transcripts are reduced in nrpb2-3 but not in nrpe1-1 or sde4-3 also imply that NRPB2 does not function together with the largest subunits of Pol IV or Pol V. Therefore, the functions of NRPB2 discovered in our study are likely those of Pol II.

Our results strongly indicate a direct role of Pol II in TGS at low-copy-number, intergenic loci. First, wholegenome microarray as well as targeted real-time RT-PCR analysis did not reveal reduced levels of expression of known genes in siRNA biogenesis or siRNA-mediated TGS. Second, Pol II is present at the chromatin of type II loci, where Pol II-dependent transcripts are made, and is associated with these transcripts. This suggests that Pol II directly generates these noncoding transcripts.

\section{Relationship between Pol II and Pol V}

Our studies show that both Pol II and Pol V are required for siRNA-mediated TGS at type II loci. What is the relationship between Pol II and Pol V? One possibility is that the two have partially redundant functions and both contribute to TGS; however, we rarely observed an additive effect of nrpb2-3 and nrpe1-1 mutations (in terms of the amplitudes of derepression), which suggests that the two have separate, nonredundant functions. The separate roles of the two polymerases at these loci are currently unknown, but we show that the presence of Pol V at region $\mathrm{B}$ of type II loci requires Pol II, whereas the presence of Pol II at type II loci is independent of Pol V. Moreover, both Pol II and Pol V are required for the recruitment of AGO4 to these loci (Wierzbicki et al. 2009; this study). We propose two models that are consistent with these observations to explain the nonredundant functions of Pol II and Pol V in TGS at type II loci. The first model is based on an additional observation that Pol V and AGO4 are associated in the Cajal body during siRNA biogenesis but are not colocalized in the nucleoplasm (Pontes et al. 2006), where TGS occurs. We hypothesize that Pol V delivers AGO4/siRNA RISCs to type II loci to allow AGO4/siRNA RISCs to interact with Pol II or Pol II transcripts, which originate in region B and perhaps extend into region A (Fig. 7A). In this model, Pol V is recruited to type II loci at region B by either Pol II transcripts or the act of Pol II transcription in region $\mathrm{B}$, and its role in TGS lies mainly in the delivery of AGO4/ siRNAs to Pol II. AGO4 is only present in region A due to the pairing between siRNAs, which are only found in region A, to Pol II transcripts. In the second model, Pol II and Pol V act sequentially to recruit AGO4/siRNA RISCs to region A (Fig. 7B). First, Pol II transcription in region B or the Pol II transcripts recruit Pol V to region $\mathrm{B}$. Pol V then transcribes through region $\mathrm{A}$, and the Pol $\mathrm{V}$ transcripts recruit AGO4/siRNA RISCs to region $\mathrm{A}$. This model is consistent with the observation that mutations in the putative active site residues in Pol V abolish TGS, 

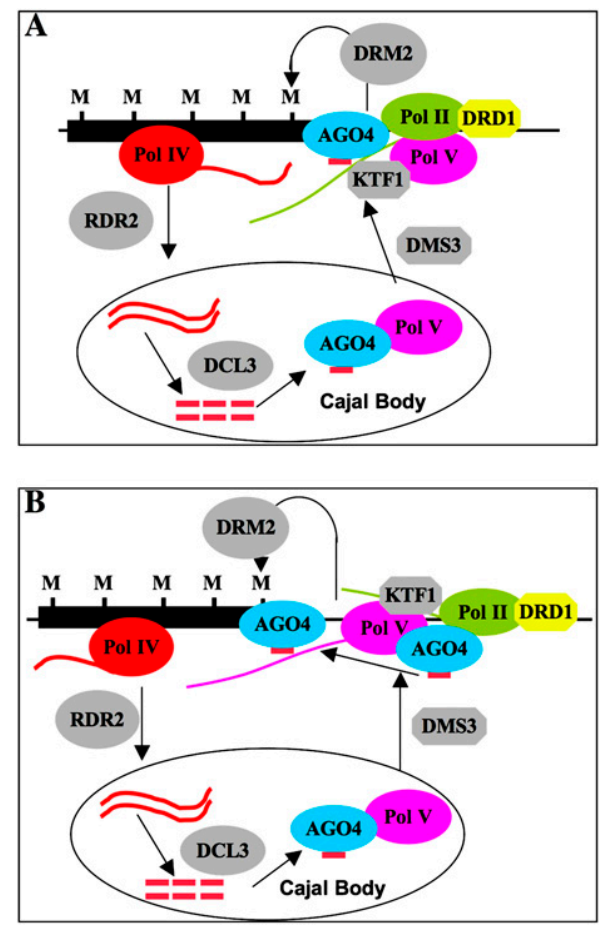

Figure 7. Models for the roles of the three polymerases in TGS at type II loci in Arabidopsis. In both models, no modifications to the prevailing views on the roles of Pol IV, RDR2, DCL3, and AGO4 are made except that we showed that Pol IV is associated with the chromatin at siRNA loci. The two models differ in the roles of Pol II and Pol V in TGS. (A) Pol II generates scaffold transcripts that originate in region $\mathrm{B}$ and that traverse region $\mathrm{A}$. The Pol II transcripts or Pol II transcription itself recruits Pol V, which is in complex with AGO4 during siRNA biogenesis in the Cajal body, to region B. Pol V delivers AGO4 to Pol II and AGO4/ siRNA RISCs localize to region A due to the sequence complementarity between siRNAs, which are only derived from region A, to Pol II transcripts. (B) Pol II generates scaffold transcripts that correspond only to region $\mathrm{B}$. These transcripts recruit Pol V to region $\mathrm{B}$ and Pol $\mathrm{V}$ makes new scaffold transcripts that traverse region A. These transcripts help anchor AGO4/siRNAs to region A. In both models, AGO4/siRNA RISCs then recruit, directly or indirectly, the DNA methyltransferase DRM2 or histone methyltransferases to result in epigenetic modifications and silencing. KTF1 may bind to Pol II transcripts to facilitate the recruitment of Pol V by Pol II transcripts. DRD1 is required for the production of Pol II transcripts. DMS3 acts downstream from Pol II transcripts to facilitate the recruitment of AGO4. (M) DNA methylation.

which suggests that Pol V transcription is necessary for TGS (Wierzbicki et al. 2008).

\section{Roles of several known genes in TGS}

Our findings also prompt the re-evaluation of current models of how several proteins-such as KTF, DRD1, and DMS3 - act in TGS. In either of our models (Fig. 7), the recently identified factor KTF1, which associates with Pol V and AGO4 and binds ssRNAs (He et al. 2009; Huang et al. 2009), may be the link between Pol II and Pol V, such that KTF1 binds Pol II transcripts to recruit Pol V to region
B. The putative chromatin remodeling factor DRD1 was thought previously to program Pol V transcription at heterochromatic loci, since Pol V occupancy at these loci (including soloLTR) requires DRD1 (Wierzbicki et al. 2008). We show that DRD1 is not specific to Pol V-it is also required for the accumulation of Pol II transcripts. Given that Pol II is required for the recruitment of Pol V to soloLTR, and that Pol II transcripts at soloLTR are diminished in the $d r d 1$ background, the previously observed dependence on DRD1 for Pol V occupancy at soloLTR is likely an indirect effect of the lack of Pol IIdependent transcripts in the mutant. DMS3, however, is not required for the production of Pol II transcripts at type II loci (this study), but is necessary for AGO4 recruitment to siRNA loci including soloLTR (Wierzbicki et al. 2009). DMS3 must act at a step downstream from Pol II transcription in the recruitment of AGO4.

\section{Feed-forward loops in siRNA biogenesis and TGS mediated by three polymerases}

Our findings provide new insights into the molecular mechanisms underlying the feed-forward loop involving siRNA biogenesis and siRNA-mediated TGS. At both type I and type II loci, Pol IV is essential for siRNA biogenesis, probably by transcribing these loci to generate siRNA precursors (Herr et al. 2005; Onodera et al. 2005; this study). The greatly reduced accumulation of type I siRNAs in nrpe1 mutants has been hypothesized to be an indirect effect of compromised DNA methylation (Pontier et al. 2005). It is thought that DNA methylation recruits Pol IV to generate more siRNAs in a feed-forward loop. siRNA accumulation at type II loci is not affected in Pol V mutants (Fig. 2; Herr et al. 2005; Pontier et al. 2005; Huettel et al. 2006), but is reduced in nrpb2-3 (Fig. 2). Therefore, Pol II, instead of Pol V, plays a role in the feedforward loop to promote siRNA production at type II loci. Since DNA methylation and/or H3K9me2 are affected at these loci in both Pol II and Pol V mutants, and yet Pol V mutants are not affected in siRNA accumulation, it is unlikely that it is the chromatin marks that recruit Pol IV in the feed-forward loop for siRNA biogenesis. Instead, we propose that it is Pol II (or the RNAs it generates) that recruits Pol IV. In fact, we show for the first time that Pol IV is associated with siRNA-generating loci, and that Pol IV occupancy at the immediate siRNA-generating region (region A) requires Pol II. By analogy, we propose that at type I loci, it is not DNA methylation that recruits Pol IV in the feed-forward loop. Instead, it is Pol V /or the Pol V-dependent transcripts) that recruits Pol IV. Alternatively, the Pol II or Pol V scaffold transcripts serve as templates for Pol IV at type II and type I loci, respectively.

\section{Evolutionary implications}

In fission yeast, Pol II is required for the biogenesis of heterochromatic siRNAs and for siRNA-directed heterochromatin assembly at pericentromeric repeats (Djupedal et al. 2005; Kato et al. 2005). Release of gene silencing, accompanied by loss of siRNA accumulation and reduced H3K9 methylation, was observed in an rpb2 mutant. 
Pol II-dependent RNA transcripts at pericentromeric repeats probably serve a dual function of being precursors to siRNAs and scaffold transcripts to recruit siRNAs. In plants, Pol IV is thought to transcribe heterochromatic loci to produce transcripts that are channeled into siRNA biogenesis (Herr et al. 2005; Onodera et al. 2005; Pontier et al. 2005). Pol V transcribes the surrounding regions of siRNA-producing loci to generate transcripts that recruit AGO4/siRNAs (Wierzbicki et al. 2008, 2009). Therefore, Pol IV and Pol V in plants appear to specialize in one of the two functions of fission yeast Pol II in TGS. Our studies showed that the plant Pol II has a central role in siRNA biogenesis and siRNA-mediated TGS at low-copy-number intergenic loci. Pol II recruits Pol IV and Pol V to regions $\mathrm{A}$ and $\mathrm{B}$ at these loci to promote siRNA biogenesis and TGS, respectively. We propose that TGS is one of the ancestral functions of the plant Pol II. If Pol II does not act at type I loci, then the silencing function of Pol II has been devolved to Pol IV and Pol V at these highcopy-number loci. This would imply that Pol IV and Pol V have evolved to recognize certain features (perhaps copy number) of these loci. Alternatively, Pol II also has a crucial role in TGS at these loci, which is not evident from the weak nrpb2-3 mutant.

\section{A silencing role of intergenic noncoding Pol II transcripts}

Transcriptome studies have revealed widespread intergenic transcription, presumably by Pol II, in animal and plant genomes to result in numerous stable and unstable noncoding transcripts (Kapranov et al. 2002, 2007; Davis and Ares 2006; Chekanova et al. 2007; Neil et al. 2009; Xu et al. 2009). Noncoding transcripts from Pol II regulate the epigenome by targeting chromatin modification machineries to specific loci. For example, many noncoding RNAs-including, but not limited to, HOTAIR and Xist-copurify with the Polycomb group PRC2 H3K27 trimethyltransferase, and, in the case of HOTAIR and Xist, the noncoding RNAs target the PRC2 to specific loci (Rinn et al. 2007; Zhao et al. 2008; Khalil et al. 2009). Our work adds to the utility of noncoding, intergenic transcription by Pol II by showing that it is a means to shape the epigenome through endogenous siRNAs.

\section{Materials and methods}

\section{Plant mutants and antibodies}

sde4-3 (SALK_128428) (Herr et al. 2005) and nrpe1-1 (previously known as nrpd1b-1, SALK_029919) (Pontier et al. 2005) seeds are kind gifts from Drs. David Baulcombe and Thierry Lagrange, respectively. The myc-AGO4 transgenic line (Li et al. 2006) was provided by Dr. Steve Jacobsen. The plasmid GST-NRPE1 CTD (Li et al. 2006; El-Shami et al. 2007) was provided by Dr. Thierry Lagrange. dms3 (SALK_068723c), ros1, and drd1 ros1 seeds were kindly provided by Dr. Jian-kang Zhu. RPB1 (catalog no. ab5408, Abcam), RPB2 (catalog no. ab10338, Abcam), H3K9me2 (catalog no. ab1220, Abcam), Flag (F7425, Sigma), myc (sc-70463, Santa Cruz Biotechnologies), and Hsp70 (SPA-818, Stressgen) antibodies were purchased from various vendors. Anti-HEN1 antibodies were generated in our laboratory. The anti-RPB1 monoclonal antibody was raised against the peptide YSPTSPS, which is repeated many times in the CTD of RPB1 from many species, including Arabidopsis. It only detected one band of the correct size for NRPB1 from total Arabidopsis protein extracts. AntiRPB2 polyclonal antibodies were raised against a peptide in the human RPB2 with 95\% sequence identity to a homologous sequence in Arabidopsis NRPB2. Anti-RPB2 antibodies only recognized one band of the expected size for NRPB2 from total Arabidopsis protein extracts.

\section{Plasmid construction}

NRPB2 genomic DNA was amplified from Col-0 genomic DNA with primers NRPB2F1 and NRPB2R1, and was cloned into the pPZP211 binary vector at the BamHI and SalI restriction sites to generate $p N R P B 2:: N R P B 2$. The plasmid was introduced into nrpb2-3 plants by Agro infiltration. The cDNA of the GW/WGrich region of NRPB2 was amplified from Col-0 and the nrpb2-3 mutant by RT-PCR with primers NRPB2F4 and NRPB2R4, and was cloned into the pGEX-2TK vector. Each of the four GW/WG motifs was changed to AA or VA by site-directed mutagenesis with primers NRPB2F6/R6, NRPB2F7/R7, NRPB2F8/R8, or NRPB2F9/R9. Expression and purification of GST fusion proteins in E. coli were done as described (Yang et al. 2007). The primer sequences are shown in Supplemental Table S3.

\section{ATH1 Affymetrix microarray analysis}

GeneChip arrays were hybridized according to the manufacturer's instructions (Affymetrix). Data analysis was done according to Horan et al. (2008). Normalization of raw intensities across all probe sets was performed in R using RMA algorithms. To calculate $P$-values for increase or decrease in expression, the Wilcoxon signed-rank test was applied to each pair of chips after normalization using R\&BioConductor (developed by Thomas Girke). A $P$-value of $\leq 0.05$ in combination with a twofold difference was used to define changes in gene expression.

\section{Real-time RT-PCR analysis of endogenous siRNA loci}

cDNA was synthesized from 3-5 $\mu$ g of total RNA using RT (Invitrogen) and oligo-dT primers. Quantitative PCR was performed in triplicate on a Bio-Rad IQ cycler apparatus with the Quantitech SYBR green kit (Bio-Rad). The primers used are listed in Supplemental Table S3.

\section{siRNA Northern blotting}

RNA isolation and hybridization for endogenous siRNAs were performed as described (Park et al. 2002). 5'-End-labeled ( ${ }^{32} \mathrm{P}$ ) antisense LNA oligonucleotides were used to detect AtSN1, TR2558, Cluster4, AtREP2, AtCopia2, SimpleHAT2, IR-71, siRNA02, and siRNA1003. To detect Cluster2 siRNAs, a DNA fragment was amplified from genomic DNA with primers Cluster2F2/Cluster2R2, gel-purified, and labeled by random priming. To detect soloLTR siRNAs, a DNA fragment was amplified from genomic DNA with soloLTRF2/soloLTRR2 primers, gel-purified, and ligated into the pGEM-T Easy vector. The plasmid was digested by SpeI and used as a template for in vitro transcription with T7 RNA polymerase in the presence of $\left[\alpha^{32} \mathrm{P}\right]$ UTP. Radioactive signals were detected and quantified with a PhosphorImager.

\section{Co-IP}

For co-IP experiments, $0.5 \mathrm{~g}$ of Ler and myc-AGO4 inflorescences were ground in liquid nitrogen and homogenized in 
$1 \mathrm{~mL}$ of protein lysis buffer $(50 \mathrm{mM}$ Tris- $\mathrm{HCl}$ at $\mathrm{pH} 7.5,150 \mathrm{mM}$ $\mathrm{NaCl}, 0.2 \%$ NP-40, 2 mM DTT, 10\% glycerol, complete protease inhibitor cocktail [Roche]). The extracts were incubated for $50 \mathrm{~min}$ at $4^{\circ} \mathrm{C}$ on a rotating wheel and centrifuged at $16,000 \mathrm{~g}$ to pellet any debris. The centrifugation was repeated three more times to remove the debris completely. The lysate was then precleared for 20 min with protein-A agarose. Half of the lysate was mixed with anti-RPB1 or anti-Myc antibodies precoupled to Protein A or Protein $\mathrm{G}$ agarose beads, respectively. The other half was mixed with beads alone. After a 2 -h incubation at $4^{\circ} \mathrm{C}$, the immune complexes were washed five times with $1 \mathrm{~mL}$ of lysis buffer. The volume was reduced to $30 \mu \mathrm{L}$ in the end. Protein samples were analyzed on $8 \%$ SDS-PAGE. Anti-myc, anti-RPB1, anti-RPB2, and anti-HEN1 antibodies were used for Western blotting.

\section{GST-NRPB2 pull-down}

GST-NRPB2 pull-down experiments were performed according to Li et al. (2006) with slight modifications. GST, GST-NRPE1 CTD, GST-NRPB2 GWR, GST-NRPB2-3 GWR, and GST-NRPB2 GWRm were expressed in E. coli BL21. Expression was induced for $3 \mathrm{~h}$ with $0.5 \mathrm{mM}$ IPTG at $30^{\circ} \mathrm{C}$. Cells were disrupted by sonication, and the fusion proteins were purified by glutathione Sepharose 4B affinity chromatography. Six-hundred microliters of inflorescence extract were applied to the beads-protein mixture $\left(30 \mu \mathrm{g}\right.$ of protein total) and incubated for $2 \mathrm{~h}$ at $4^{\circ} \mathrm{C}$ on a rotating wheel. The beads were washed five times with immunoprecipitation lysis buffer. Proteins bound by the beads and those in the supernatant were resolved in $8 \%$ SDS-PAGE gels and subjected to Western blotting.

\section{ChIP}

ChIP was performed according to Xie et al. (2004) and Huettel et al. (2006). The results shown were reproduced in three biological replicates. The primer sets used for the PCR are listed in Supplemental Table S3.

\section{Detection of Pol II-dependent transcripts by RT-PCR}

RT-PCR experiments were done according to Wierzbicki et al. (2008), with some modifications. cDNA was synthesized from $5 \mu \mathrm{g}$ of total RNA using RT (Invitrogen) and gene-specific primers. PCR was performed using hot-start platinum Taq DNA polymerase (Invitrogen). For siR02, the temperature-cycling scheme was as follows: $30 \mathrm{sec}$ at $94^{\circ} \mathrm{C}, 30 \mathrm{sec}$ at $54^{\circ} \mathrm{C}, 30 \mathrm{sec}$ at $72^{\circ} \mathrm{C}, 38$ cycles, and a final extension for $10 \mathrm{~min}$ at $72^{\circ} \mathrm{C}$. The PCR conditions for AtSN1 B, soloLTR B, and IGN5 B were according to Wierzbicki et al. (2008). The results shown were reproduced at least three times. The primers used are listed in Supplemental Table S3.

\section{RIP}

RIP was performed according to Wierzbicki et al. (2008). The primers used are listed in Supplemental Table S3.

\section{Acknowledgments}

We are grateful to David Baulcombe, Steve Jacobsen, Thierry Lagrange, Craig Pikaard, and Jian-Kang Zhu for sharing plant material and plasmids. We thank Jian-Kang Zhu, So Youn Won, Vanitharani Ramachandran, and Theresa Dinh for comments on the manuscript. The work was supported by grants from the National Institutes of Health (GM61146) and National Science Foundation (MCB-0718029) to X.C.

\section{References}

Cao X, Aufsatz W, Zilberman D, Mette MF, Huang MS, Matzke M, Jacobsen SE. 2003. Role of the DRM and CMT3 methyltransferases in RNA-directed DNA methylation. Curr Biol 13: 2212-2217.

Chekanova JA, Gregory BD, Reverdatto SV, Chen H, Kumar R, Hooker T, Yazaki J, Li P, Skiba N, Peng Q, et al. 2007. Genome-wide high-resolution mapping of exosome substrates reveals hidden features in the Arabidopsis transcriptome. Cell 131: 1340-1353.

Davis CA, Ares M Jr. 2006. Accumulation of unstable promoterassociated transcripts upon loss of the nuclear exosome subunit Rrp6p in Saccharomyces cerevisiae. Proc Natl Acad Sci 103: 3262-3267.

Djupedal I, Portoso M, Spahr H, Bonilla C, Gustafsson CM, Allshire RC, Ekwall K. 2005. RNA Pol II subunit Rpb7 promotes centromeric transcription and RNAi-directed chromatin silencing. Genes \& Dev 19: 2301-2306.

Ebbs ML, Bender J. 2006. Locus-specific control of DNA methylation by the Arabidopsis SUVH5 histone methyltransferase. Plant Cell 18: 1166-1176.

Ebbs ML, Bartee L, Bender J. 2005. H3 lysine 9 methylation is maintained on a transcribed inverted repeat by combined action of SUVH6 and SUVH4 methyltransferases. Mol Cell Biol 25: 10507-10515.

El-Shami M, Pontier D, Lahmy S, Braun L, Picart C, Vega D, Hakimi MA, Jacobsen SE, Cooke R, Lagrange T. 2007. Reiterated WG/GW motifs form functionally and evolutionarily conserved ARGONAUTE-binding platforms in RNAirelated components. Genes \& Dev 21: 2539-2544.

Hamilton A, Voinnet O, Chappell L, Baulcombe D. 2002. Two classes of short interfering RNA in RNA silencing. EMBO J 21: 4671-4679.

He XI, Hsu YF, Zhu S, Wierzbicki AT, Pontes O, Pikaard CS, Liu HL, Wang CS, Jin H, Zhu JK. 2009. An effector of RNA-directed DNA methylation in Arabidopsis is an ARGONAUTE 4- and RNA-binding protein. Cell 137: 498-508.

Herr AJ, Jensen MB, Dalmay T, Baulcombe DC. 2005. RNA polymerase IV directs silencing of endogenous DNA. Science 308: $118-120$.

Horan K, Jang C, Bailey-Serres J, Mittler R, Shelton C, Harper JF, Zhu JK, Cushman JC, Gollery M, Girke T. 2008. Annotating genes of known and unknown function by large-scale coexpression analysis. Plant Physiol 147: 41-57.

Huang L, Jones AM, Searle I, Patel K, Vogler H, Hubner NC, Baulcombe DC. 2009. An atypical RNA polymerase involved in RNA silencing shares small subunits with RNA polymerase II. Nat Struct Mol Biol 16: 91-93.

Huettel B, Kanno T, Daxinger L, Aufsatz W, Matzke AJ, Matzke M. 2006. Endogenous targets of RNA-directed DNA methylation and Pol IV in Arabidopsis. EMBO I 25: 28282836.

Kanno T, Mette MF, Kreil DP, Aufsatz W, Matzke M, Matzke AJ. 2004. Involvement of putative SNF2 chromatin remodeling protein DRD1 in RNA-directed DNA methylation. Curr Biol 14: 801-805.

Kanno T, Huettel B, Mette MF, Aufsatz W, Jaligot E, Daxinger L, Kreil DP, Matzke M, Matzke AJ. 2005. Atypical RNA polymerase subunits required for RNA-directed DNA methylation. Nat Genet 37: 761-765.

Kanno T, Bucher E, Daxinger L, Huettel B, Bohmdorfer G, Gregor W, Kreil DP, Matzke M, Matzke AJ. 2008. A structuralmaintenance-of-chromosomes hinge domain-containing protein is required for RNA-directed DNA methylation. Nat Genet 40: 670-675. 
Kapranov P, Cawley SE, Drenkow J, Bekiranov S, Strausberg RL, Fodor SP, Gingeras TR. 2002. Large-scale transcriptional activity in chromosomes 21 and 22. Science 296: 916-919.

Kapranov P, Cheng J, Dike S, Nix DA, Duttagupta R, Willingham AT, Stadler PF, Hertel J, Hackermuller J, Hofacker IL, et al. 2007. RNA maps reveal new RNA classes and a possible function for pervasive transcription. Science 316: 1484-1488.

Kato H, Goto DB, Martienssen RA, Urano T, Furukawa K, Murakami Y. 2005. RNA polymerase II is required for RNAidependent heterochromatin assembly. Science 309: 467-469.

Khalil AM, Guttman M, Huarte M, Garber M, Raj A, Rivea Morales D, Thomas $\mathrm{K}$, Presser A, Bernstein BE, van Oudenaarden A, et al. 2009. Many human large intergenic noncoding RNAs associate with chromatin-modifying complexes and affect gene expression. Proc Natl Acad Sci 106: 11667-11672.

Lahmy S, Pontier D, Cavel E, Vega D, El-Shami M, Kanno T, Lagrange T. 2009. PolV(PolIVb) function in RNA-directed DNA methylation requires the conserved active site and an additional plant-specific subunit. Proc Natl Acad Sci 106: 941-946.

Li CF, Pontes O, El-Shami M, Henderson IR, Bernatavichute YV, Chan SW, Lagrange T, Pikaard CS, Jacobsen SE. 2006. An ARGONAUTE4-containing nuclear processing center colocalized with Cajal bodies in Arabidopsis thaliana. Cell 126: 93-106.

Malagnac F, Bartee L, Bender J. 2002. An Arabidopsis SET domain protein required for maintenance but not establishment of DNA methylation. EMBO J 21: 6842-6852.

Moazed D. 2009. Small RNAs in transcriptional gene silencing and genome defence. Nature 457: 413-420.

Mosher RA, Schwach F, Studholme D, Baulcombe DC. 2008. PolIVb influences RNA-directed DNA methylation independently of its role in siRNA biogenesis. Proc Natl Acad Sci 105: 3145-3150.

Naumann K, Fischer A, Hofmann I, Krauss V, Phalke S, Irmler K, Hause G, Aurich AC, Dorn R, Jenuwein T, et al. 2005. Pivotal role of AtSUVH2 in heterochromatic histone methylation and gene silencing in Arabidopsis. EMBO I 24: 14181429.

Neil H, Malabat C, d'Aubenton-Carafa Y, Xu Z, Steinmetz LM, Jacquier A. 2009. Widespread bidirectional promoters are the major source of cryptic transcripts in yeast. Nature 457: $1038-1042$.

Onodera Y, Haag JR, Ream T, Nunes PC, Pontes O, Pikaard CS. 2005. Plant nuclear RNA polymerase IV mediates siRNA and DNA methylation-dependent heterochromatin formation. Cell 120: 613-622.

Onodera Y, Nakagawa K, Haag JR, Pikaard D, Mikami T, Ream T, Ito Y, Pikaard CS. 2008. Sex-biased lethality or transmission of defective transcription machinery in Arabidopsis. Genetics 180: 207-218.

Park W, Li J, Song R, Messing J, Chen X. 2002. CARPEL FACTORY, a Dicer homolog, and HEN1, a novel protein, act in microRNA metabolism in Arabidopsis thaliana. Curr Biol 12: 1484-1495.

Pontes O, Li CF, Nunes PC, Haag J, Ream T, Vitins A, Jacobsen SE, Pikaard CS. 2006. The Arabidopsis chromatin-modifying nuclear siRNA pathway involves a nucleolar RNA processing center. Cell 126: 79-92.

Pontier D, Yahubyan G, Vega D, Bulski A, Saez-Vasquez J, Hakimi MA, Lerbs-Mache S, Colot V, Lagrange T. 2005. Reinforcement of silencing at transposons and highly repeated sequences requires the concerted action of two distinct RNA polymerases IV in Arabidopsis. Genes \& Dev 19: $2030-2040$.
Ream TS, Haag JR, Wierzbicki AT, Nicora CD, Norbeck AD, Zhu JK, Hagen G, Guilfoyle TJ, Pasa-Tolic L, Pikaard CS. 2009. Subunit compositions of the RNA-silencing enzymes Pol IV and Pol V reveal their origins as specialized forms of RNA polymerase II. Mol Cell 33: 192-203.

Rinn JL, Kertesz M, Wang JK, Squazzo SL, Xu X, Brugmann SA, Goodnough LH, Helms JA, Farnham PJ, Segal E, et al. 2007. Functional demarcation of active and silent chromatin domains in human HOX loci by noncoding RNAs. Cell 129: 1311-1323.

Volpe TA, Kidner C, Hall IM, Teng G, Grewal SI, Martienssen RA. 2002. Regulation of heterochromatic silencing and histone H3 lysine-9 methylation by RNAi. Science 297: 1833-1837.

Wierzbicki AT, Haag JR, Pikaard CS. 2008. Noncoding transcription by RNA polymerase $\mathrm{Pol} \mathrm{IVb} / \mathrm{Pol} \mathrm{V}$ mediates transcriptional silencing of overlapping and adjacent genes. Cell 135: 635-648.

Wierzbicki AT, Ream TS, Haag JR, Pikaard CS. 2009. RNA polymerase $\mathrm{V}$ transcription guides ARGONAUTE4 to chromatin. Nat Genet 41: 630-634.

Xie Z, Johansen LK, Gustafson AM, Kasschau KD, Lellis AD, Zilberman D, Jacobsen SE, Carrington JC. 2004. Genetic and functional diversification of small RNA pathways in plants. PLOS Biol 2: E104. doi: 10.1371.journal.pbio.0020104.

$\mathrm{Xu} \mathrm{Z,} \mathrm{Wei} \mathrm{W,} \mathrm{Gagneur} \mathrm{J,} \mathrm{Perocchi} \mathrm{F,} \mathrm{Clauder-Munster} \mathrm{S,}$ Camblong J, Guffanti E, Stutz F, Huber W, Steinmetz LM. 2009. Bidirectional promoters generate pervasive transcription in yeast. Nature 457: 1033-1037.

Yang Z, Vilkaitis G, Yu B, Klimasauskas S, Chen X. 2007. Approaches for studying microRNA and small interfering RNA methylation in vitro and in vivo. Methods Enzymol 427: 139-154.

Zhang X, Henderson IR, Lu C, Green PJ, Jacobsen SE. 2007. Role of RNA polymerase IV in plant small RNA metabolism. Proc Natl Acad Sci 104: 4536-4541.

Zhao J, Sun BK, Erwin JA, Song JJ, Lee JT. 2008. Polycomb proteins targeted by a short repeat RNA to the mouse $\mathrm{X}$ chromosome. Science 322: 750-756.

Zheng X, Zhu J, Kapoor A, Zhu JK. 2007. Role of Arabidopsis AGO6 in siRNA accumulation, DNA methylation and transcriptional gene silencing. EMBO J 26: 1691-1701.

Zilberman D, Cao X, Jacobsen SE. 2003. ARGONAUTE4 control of locus-specific siRNA accumulation and DNA and histone methylation. Science 299: 716-719. 


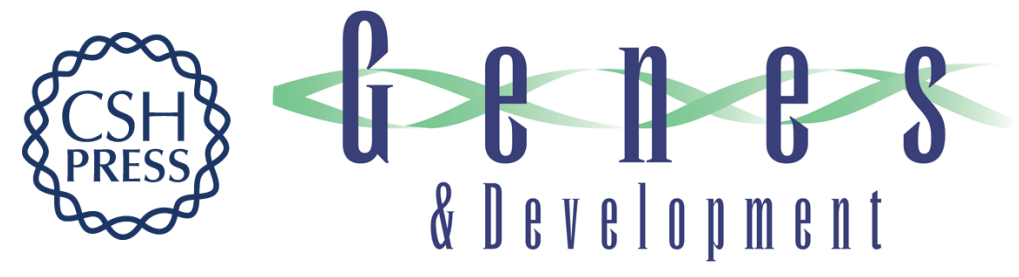

\section{Intergenic transcription by RNA Polymerase II coordinates Pol IV and Pol V in siRNA-directed transcriptional gene silencing in Arabidopsis}

Binglian Zheng, Zhengming Wang, Shengben Li, et al.

Genes Dev. 2009, 23: originally published online November 30, 2009

Access the most recent version at doi:10.1101/gad.1868009

\section{Supplemental http://genesdev.cshlp.org/content/suppl/2009/10/29/gad.1868009.DC1 Material}

References This article cites 44 articles, 21 of which can be accessed free at: http://genesdev.cshlp.org/content/23/24/2850.full.html\#ref-list-1

\section{License}

Email Alerting

Service

Receive free email alerts when new articles cite this article - sign up in the box at the top right corner of the article or click here.

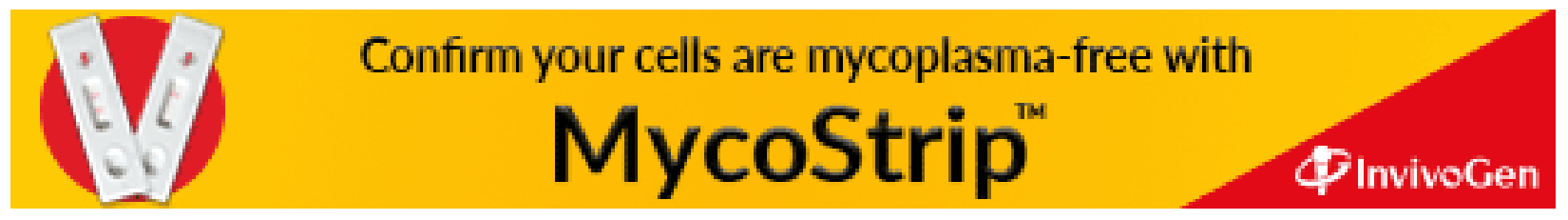

